\title{
A ETICIDADE HEGELIANA
}

Thadeu Weber*

SÍNTESE - O artigo discute a critica de Hegel ao "formalismo" da ética kantiana. Ao distinguir moralidade de eticidade, mostra que um principio ético deve passar pelo processo de mediação das vontades a fim de constituir-se em lei universal. Apresenta a Familia, a Sociedade Civil e o Estado como instâncias mediadoras ou determinações da Eticidade Hegelina.

ABSTRACT - The article draws upon Hegel's critique to the "formalism" of Kant's ethics. In the distinction between morality and ethics, it shows that and ethical principle must permeate the process of mediation of wills in order to become a universal law. Finally, it presents Family, Civil Society and State as mediators or determinants of the principles of Hegel's ethics.

\section{1 - A crítica à ética kantiana}

O debate em torno de um dos aspectos centrais da crítica de Hegel à ética kantiana - a questão do formalismo - nos reporta a um dos principais parágrafos da Filosofia do Direito, o de n. 135. A discussão dessa problemática, no entanto, requer que a situemos no devido contexto do sistema.

A Filosofia do Direito de Hegel trata do desdobramento ou das determinações da Idéia de liberdade, princípio nela pressuposto mas demonstrado na Ciência da Lógica e na Enciclopédia. Trata-se de uma exposição especulativa dos momentos do desenvolvimento da Idéia da vontade livre ou das determinações necessárias do conceito do Direito; isto é, mostra como a liberdade, enquanto idéia filosófica, concretiza-se ao nivel das estruturas jurídicas. As formas do Direito que se seguem na exposição do Espírito Objetivo (ou Filosofia do Direito) se devem ao fato de o desdobramento do conceito da liberdade processar-se em diferentes etapas. É importante enfatizar que Hegel se propõe a fazer uma ciência filosófica do Direito e não uma ciência do Direito. Pretende expor as estruturas concretas do Direito tendo por base um princípio de organização que representa o fio condutor da reconstrução. A ciência do Direito faz parte da Filosofia. Isto significa dizer que a Idéia de liberdade a ser concretizada pelo Direito é fornecida pela Filosofia.

São três as partes que constituem a Filosofia do Direito:

1. O Direito Abstrato apresenta as formas concretas e imediatas da realização da Idéia da liberdade. Trata-se de formas ainda indeterminadas, uma vez que não existe mediação social. Incluem-se aí a propriedade, o contrato e a injustiça.

2. A moralidade trata da autodeterminação da vontade livre, dos propósitos e intenções que movem o indivíduo. Trata das condições da responsabilidade subjetiva. A vontade reconhece como seu somente aquilo que sabia e aquilo que queria fazer. Alguém só pode ser responsabilizado por um ato que quis fazer e cujas conseqüên-

- Professor no Instituto de Filosofia e Ciências Humanas da PUCRS. 
cias podia prever. Em Kant, o que importa é a intenção e não as conseqüências. Na Crítica da Razão Prática (Kritik der praktischen Vernunft - KpV) lemos: "O que unicamente interessa aqui é a determinação da vontade e o princípio determinante da máxima desta enquanto vontade livre, e não o resultado" (KpV p. 159). Em outro lugar escreve: "A regra prática é sempre um produto da razão, porque prescreve a ação como meio para o efeito, como intenção (Absicht)" (KpV p. 126).

3. A eticidade trata da mediação social da liberdade, isto é, das relações objetivas, da dimensão supra-individual. É somente nesta terceira etapa que se realiza o conceito do Direito.

A distinção entre moralidade e eticidade, em Hegel, é de fundamental importância para se compreender a crítica à Kant. Para aquele, este permaneceu no plano da subjetividade (formal e a priori) e não passa para o nivel das determinações objetivas, condição imprescindivel para se poder falar em conteúdo da lei moral.

Hegel concorda com a tese kantiana segundo a qual é essencial que a autodeterminação da vontade seja a raiz do dever. A Ciência da Lógica já se encarregara de mostrar que a liberdade se realiza no conceito enquanto autodeterminação. O Conceito, como reino da subjetividade, é o reino da liberdade. É o retorno do Absoluto sobre si mesmo. O Absoluto estando consigo mesmo é liberdade, porque é autodeterminação. Em outras palavras, o Conceito é livre, porque é auto-causação (cf. Weber, 1993). Mas "permanecer no mero ponto de vista moral sem passar ao conceito de eticidade converte aquele mérito em um vazio formalismo e a ciência moral em uma retórica acerca do dever pelo dever mesmo" (Rechtsphilosophie - Filosofia do Direito, doravante $R p h, \& 135)$. Eis o alvo central da crítica a Kant, uma vez que este sustenta que o Dever não é empírico, ou seja, não pode ser tirado da experiência, mas é um a priori da razão. Esta tese é retomada constantemente por Kant, na Crítica da Razão Prática. Pode-se referir, por exemplo, o Problema II do Capítulo I, onde o autor sustenta que a "razão pura deve, por si mesma apenas, ser prática, isto é, sem pressuposição de um sentimento qualquer, por conseguinte sem representações do agradável ou desagradável enquanto matéria da faculdade de desejar, que é sempre uma condição empírica dos princípios, deve poder determinar a vontade pela simples forma da regra prática" (KpV p. 132). O Teorema III insiste com mais veemência na necessidade de que a base da determinação da vontade seja a forma da lei e não a matéria. É a "forma legisladora universal" que deve ser tomada como princípio determinante da vontade. A consciência desta lei fundamental (o imperativo categórico) é um "fato da razão". Ainda no mesmo Teorema podemos ler: "mesmo se nenhum outro princípio determinante da vontade pode servir de lei, a não ser apenas essa forma legisladora universal, uma tal vontade deve conceber-se como totalmente independente da lei natural dos fenômenos nas suas relações reciprocas, a saber, da lei da causalidade. Uma tal independência, porém, chama-se liberdade no sentido mais estrito, isto é, o transcendental. Por conseguinte, uma vontade, à qual só a pura forma legisladora da máxima pode servir de lei, é uma vontade pura" (KpV p. 138). O princípio único da moralidade consiste "na independência a respeito de toda a matéria da lei (isto é, de um objeto desejado) e ao mesmo tempo, na determinação do livre arbítrio pela simples forma legisladora universal, de que uma máxima deve ser capaz" (KpV p. 144).

A crítica de Hegel a propósito de tal "formalismo" fica evidenciada no texto que segue: "Se se parte da determinação do dever como falta de contradição ou concordância formal consigo mesmo, que não é outra coisa que o estabelecimento da indeterminação abstrata, [...] não se pode passar para a determinação de deveres particu- 
lares. Tampouco há nesse principio nenhum critério que permita decidir se um conteúdo particular que se apresente ao agente é ou não um dever. Pelo contrário, todo modo de proceder injusto e imoral pode ser justificado desta maneira" (Rph, \& 135). Uma indeterminação abstrata ainda nem sequer começou seu processo de mediação. Logo, não pode haver contradição. Ora, sem contradição não há dialética, isto é, não há superação. Em Kant não há mediação para a determinação da vontade pela lei moral. Ele descreve: "O essencial de todo o valor moral das ações depende de que a lei moral determina imediatamente a vontade" (KpV p. 191). Uma máxima deve poder converter-se em lei universal para que o ato possa ser tido como moral. Em outras palavras, não pode haver contradição entre a máxima e a lei universal. Isto tem validade apriorística e não admite exceções.

Para Hegel a contradição só aparece no momento da determinação ou da concretização da Idéia da liberdade. A determinação de deveres particulares requer um princípio orientador que sirva de referencial teórico a partir do qual se possa avaliar um ato concreto ou conteúdo particular. A contradição só pode surgir se um ato particular contrariar um principio previamente estabelecido. Este princípio, no entanto, não pode ser uma abstração vazia de conteúdo, pois nesse caso tanto pode ser justificado um ato moral, como um ato imoral. Alguém poderia querer a universalização de sua máxima do agir a fim de justificar a sua ação. A corrupção pode ser tomada como exemplo. Tomemos a argumentação de Hegel: "Que não haja nenhuma propriedade não contém por si nenhuma contradição, como tampouco o encerra o fato de que este povo singular ou esta família não exista, ou que em geral não viva nenhum homem. Se, por outro lado, se admite e supõe que a propriedade e a vida humana devem existir e ser respeitadas, então cometer um roubo ou assassinato é uma contradição; uma contradição só pode surgir com algo que é, com um conteúdo que subjaz previamente como princípio firme. Somente com referência a um princípio semelhante uma ação é concordante ou contraditória" (Rph, \& 135). É importante evidenciar que o desrespeito para com a propriedade privada somente constitui um ato injusto e imoral em vista do princípio segundo o qual "devemos respeitar a propriedade alheia". A ausência desse princípio numa determinada sociedade ou Estado permite a posse e o uso por quem assim o desejar, sem que isto implique numa contradição. Um dever que deve ser querido pelo dever mesmo e não por causa de um conteúdo, consiste na eliminação de todo conteúdo e determinação. A proposição "age de tal forma que tua máxima possa ser tomada como princípio universal" seria muito boa se já tivéssemos a nossa disposição princípios determinados sobre o que se deve fazer (cf. Rph, \& 135, Zus. - Zusatz - acréscimo). Mas como saber disso se só tivermos como referencial um imperativo formal, isto é, sem a determinação de um conteúdo empírico? 0 imperativo categórico kantiano, enquanto desprovido de conteúdo concreto, não provoca nenhuma contradição e, por isso, não há movimento de superação possivel. É um princípio indeterminado. Na perspectiva hegeliana, porém, forma e conteúdo coabitam. Com isso cai a validade apriorística do imperativo categórico de Kant. À forma da máxima moral deve-se juntar o conteúdo da ação. Na prática, encontramos dificuldades na aplicação da lei moral kantiana, pelo menos em grande parte da nossa vida concreta. 


\section{2- A eticidade hegeliana}

Hegel pretende superar a moralidade kantiana com a eticidade. É nesta fase que se dá a objetivação e, portanto, a determinação do conteúdo moral. No \& 142 da Filosofia do Direito escreve: "O que é eticidade? Que minha vontade seja posta como adequada ao conceito e com isso superada e guardada (aufgehoben) sua subjetividade". Ora, esta situa-se ao nível da vontade imediata. Exige mediação social, isto é, objetivação e desdobramento. A eticidade não se situa ao nivel das opiniōes subjetivas e caprichos pessoais, mais ao nível das instituições e das leis existentes em si para si. 0 conteúdo do ético é, portanto, necessário e está acima das opiniões contingentes. Por isso, o indivíduo é agora considerado como "membro" (Mitglied). É preciso insistir na necessidade de objetivação da moralidade subjetiva. Minha vontade livre tem que ser mediada pela vontade livre do outro, a fim de se universalizar. $O$ imediato tem que ser mediado para que se possa estabelecer um princípio ético universal. Para que um princípio possa ser universalizado, tem que passar pelo processo de mediação social. A eticidade trata das determinações objetivas da liberdade e não pode ser confundida com as vontades particulares imediatas. Resulta daí, como se pode ver, uma limitação das liberdades individuais, na medida de seu desdobramento e realização nas instituições sociais. "O dever que obriga só pode aparecer como uma limitação frente a subjetividade indeterminada ou liberdade abstrata" (Rph, \& 149). As vontades subjetivas imediatas devem ser superadas enquanto imediatas, para que a convivência seja possível.

A distinção hegeliana entre primeira e segunda natureza é esclarecedora. A primeira natureza diz respeito às vontades imediatas naturais, ao passo que a segunda inclui as determinações da eticidade. O ético é um modo de atuar universal porque passou pelo processo de mediação. O hábito, no ético, se converte em uma segunda natureza que ocupa o lugar da primeira vontade meramente natural. "O costume é o que o Direito e a Moral ainda não são: espirito. No Direito a particularidade não é ainda a particularidade do Conceito, mas somente vontade natural [...] Do ponto de vista ético, a vontade existe como vontade do espírito e tem um conteúdo substancial que lhe corresponde. A Pedagogia é a arte de fazer éticos os homens; considera o homem como natural e lhe mostra o caminho para voltar a nascer, para converter sua primeira natureza em uma segunda natureza espiritual, de tal maneira que o espiritual se converta em hábito" (Rph, \& 151, Zus).

O texto é de indiscutível relevância. Mostra como a eticidade "supera e conserva" o Direito e a Moralidade na realização do princípio da liberdade. Revela, sobretudo, que o natural e imediato, somente ao ser submetido ao processo de mediação, pode dar lugar a um conteúdo substancial, ausente na lei moral kantiana. O racional é o substancial, o espiritual. O natural é o imediato, a vontade subjetiva. A vontade particular desaparece na substância ética na medida em que reconhece que sua dignidade nela se funda. Mas este desaparecimento não significa eliminação da particularidade e, sim, elevação a um nível superior.

A questão central que sempre se impõe, no entanto, é esta: Como conciliar as vontades imediatas com a vontade substancial (universal), sem o sacrificio de uma das partes? Se a realização da liberdade implica em objetivação ou concretização, isto não significa que a particularidade deva ser eliminada. No \& 155 da Filosofia do Direito Hegel evidencia a mútua restrição entre direitos e deveres, a fim de possibilitar a realização da substancialidade ética. "Nesta identidade da vontade universal e da von- 
tade particular coincidem o Dever e o Direito; por meio do ético o homem tem direitos na medida em que tem deveres e deveres na medida em que tem direitos" ( $R p h$, \& 155). O Direito e a Moral são instâncias insuficientes para realizar esta coincidência. Só a eticidade, na medida em que estabelece a identidade entre direitos e deveres, é capaz de cumprir esta tarefa. "O escravo não pode ter deveres, só o homem livre pode tê-los" (Rph, \& 155). Na substância ética a vontade imediata (natural) foi elevada ao nivel de vontade universal porque passou pelo processo de mediação social (leis e instituições); isto é, passou pelo processo de efetivação, onde foi determinado seu conteúdo. "O racional é o efetivo e o efetivo é o racional" ( $R p h$, Prefácio). $O$ racional não é o imediato, ou seja, o real. Minha vontade imediata tem que passar pelo processo de efetivação para tornar-se vontade substancial. Qualquer pretensão de verdade deve ser submetida ao processo de mediação (das vontades). Na mediação há negação e superação a um nivel superior de determinação e, portanto, universalização. A figura do Senhor e do Servo, apresentada por Hegel na Fenomenologia do Espirito, merece ser lembrada: para que a consciência fique autoconsciência é preciso que haja a passagem pela outra consciência. Há uma relativização da autonomia e independência de cada uma das consciências (Senhor e Servo). Mas esta é uma condição necessária para que ocorra a superação dos antagonismos entre as verdades imediatas.

\section{3 - As determinações da eticidade}

\section{1 - A familia}

Se a eticidade trata do desdobramento da liberdade nas instituições sociais, a familia pode ser definida como "o espírito ético imediato (Rph, \& 157). Nela o individuo passa a ser considerado como "membro de" uma comunidade. É o campo da eticidade natural.

A família é constituída pelo casamento, a propriedade familiar e a educação dos filhos. O casamento é a relação ética imediata, ou seja, ele se constitui a partir do amor natural, que é o sentimento considerado no seu momento imediato. $O$ reconhecimento de duas vontades livres na forma de contrato constitui o amor jurídico. São, no entanto, momentos insuficientes para fazer do casamento uma instituição da sociedade e base ética do Estado. Exige-se o que Hegel chama de "amor jurídico-ético", no qual desaparece o passageiro e o meramente subjetivo (cf. $R p h, \& 161$ ). É o momento da síntese, no qual os momentos anteriores estão superados e guardados.

A propriedade familiar é a realidade externa da família. É, portanto, todo potencial capaz de cumprir as tarefas próprias da familia. Ela não visa a simples satisfação de carências subjetivas de individuos, mas, sim, a de uma "pessoa substancial" (a familia).

A educação dos filhos representa a manifestação objetiva do amor dos pais. Neles se completa a dialética da família. A Educação visa uma disciplina capaz de formar um consciência e vontade coletivas, preparando-os para a convivência social.

A dissolução da família, que ocorre com a maioridade dos filhos, abre um espaço a ser preenchido pela sociedade civil. É importante observar que, no movimento dialético, é a insuficiência de um momento que reporta a outro. É exatamente o que ocorre na relação família e sociedade civil. 


\section{2 - A sociedade civil}

Se a família tem como característica a eticidade natural (imediata), a sociedade civil baseia-se na superação dessa eticidade, por causa da mediação, e representa uma conquista da eticidade substancial, mas que ainda é apenas aparente, ou seja, ela aparece como uma estrutura ética substancial, porque caracterizada pelo individualismo, cuja preocupação fundamental é a satisfação dos interesses pessoais (cf. também Dotti, 1983, p. 125). Por isso ela é um "campo de batalha do interesse privado individual de todos contra todos (Rph, \& 289).

Dois são os princípios que requerem mediação na sociedade civil: o primeiro é a pessoa concreta, enquanto particularidade de interesses; o segundo é o contexto social, ou seja, cada pessoa particular somente se satisfaz por meio da outra, sendo "obrigada a passar pela forma da universalidade" (Rph, \& 182). A questão que se coloca é esta: como conciliar os interesses particulares com os da coletividade? Compete à sociedade civil constituir a mediação social da liberdade. $\mathrm{O}$ enquadramento social é condição de possibilidade da realização da vontade livre.

A sociedade civil, no entanto, é forma exterior de relacionamento social, ainda destituida de essência ética. O que a caracteriza é a satisfação das necessidades pessoais ou de grupos, sem que haja a preocupação com o substancial. O interesse pelo benefício pessoal ou de determinado grupo sobrepõe-se ao interesse da coletividade, não se chegando a elaborar "um sistema verdadeiramente ético de relações inter-humanas" (Dotti, 1983, p. 125). Por isso, Hegel fala em mundo da aparência da eticidade; aparência essa necessária para chegar à estrutura essencial. Isso significa dizer que sociedade civil só pode ser pensada como o aparecer do Estado. Por outra, o Estado não pode ser compreendido sem sua base na sociedade civil ou, ainda, a lógica do Estado de Direito não pode ser separada da lógica da sociedade civil. Está, assim, justificado por que, na ordem da exposição da Filosofia do Direito, a sociedade civil se situa entre a família e o Estado. A sociedade civil reverte e exige uma outra instância capaz de realizar a eticidade. É a mesma estrutura apresentada na Ciência da Lógica. À "lógica do ser" corresponde, como equivalente, a familia como o imediato e natural; à "lógica da essência", a sociedade civil com a aparência da substancialidade ética, e à "lógica do conceito", o Estado como detentor da eticidade; ou seja, como o lugar da liberdade realizada, isto é, a necessidade compreendida do Conceito. Cumpre destacar que, no Direito, o objeto é a pessoa; na Moral, é o sujeito; na família, é o "membro de" e, na sociedade civil, é o cidadão.

Não é pretensão desse trabalho entrar no detalhamento das determinações da sociedade civil, tais como: 0 sistema das necessidades, a subdivisão das classes, a administração da justiça, a administração pública e as corporações. Desenvolvo esta temática no livro Hegel: Liberdade, Estado e História.

\section{3 - O Estado}

Se na sociedade civil há um predomínio dos interesses particulares, o Estado é a organização do poder que persegue fins universais (cf. Bobbio, 1986, p. 152). Dentro das determinações da Idéia da liberdade, o Estado aparece como "verdadeiro fundamento", isto é, como lugar supremo capaz de garantir toda a estrutura da Filosofia do Direito. A família e as corporações constituem-se nas suas bases éticas. Assim como na Ciência da Lógica o Conceito, na qualidade de princípio vital intelectual, é o único referencial, o Conceito do Estado é o único referencial garantidor da estrutura da Filo- 
sofia do Direito. Aliás, sobre isso convém citar Marx: "A lógica não serve para justificar o Estado; pelo contrário, é o Estado que serve para justificar a lógica" (Marx, 1983, p. 27).

Hegel quer mostrar que o Estado é a "realidade efetiva da Idéia ética" (Rph, \& 257). Ele se constitui na "autoconsciência particular elevada à sua universalidade". É, por isso, o racional por excelência. Pelo fato de o Estado ser o Espírito Objetivo, o individuo só tem "objetividade, verdade e eticidade" se for parte dele. A determinação dos indivíduos é levar uma vida universal. Dessa forma, o Estado representa o fim dos antagonismos, ou melhor, as contradições estão perfeitamente administradas.

Há que se fazer, no entanto, um distinção fundamental entre Estado Absoluto e Estados históricos. O primeiro é o ideal, o conceitual, o Estado pensado; o espaço no qual se realiza a "substância ética". Os segundos são Estados empiricamente existentes; são as concretizações do Estado pensado. O Estado Absoluto não está plenamente realizado. Os Estados históricos são a concretização do Estado Absoluto, mas não a realização plena. O que temos em nível de realidade é o não-ser do Estado. "Todo efetivo é racional" e não todo real é racional. A realidade diz respeito ao imediato, factual, ao não-ser do Estado. A efetividade inclui realidade efetiva, mediada; inclui realização conceitual do Estado. O Estado Absoluto é a realização conceitual do Estado, mas não realização empírica plena. Os Estados históricos são as realizações parciais da Idéia do Estado. Em outras palavras, os Estados históricos são o "aparecer" do Estado Racional. S. Avineri fala em "aproximação" da Idéia do Estado (cf. 1974, p. 394).

Quando Hegel diz que o Estado é a realização plena da liberdade, que a essência do Estado é a liberdade, que o Estado representa a realização da "liberdade substancial", está, evidentemente, referindo-se ao Estado do ponto de vista lógico, racional, conceitual (cf. também, Rosenfield, 1983, p. 219). Querer identificar esse Estado com o Estado prussiano (que é histórico) é não interpretar devidamente a relação entre o ideal e o real, entre o dever-ser e o que é, entre o conceitual e o empírico. Em Hegel, o racional é o efetivo, mas com isso não está dito que o real seja a realização efetiva e completa do ideal. O real deve ser visto como o ainda não-ser do ideal, que move o real. O Estado Racional, sendo o "verdadeiro fundamento", tem a função de impulsionar os Estados históricos e, ao mesmo tempo, servir de força de atração para a gradativa conquista da liberdade. O Estado Racional, como ideal, está se efetivando.

É importante chamar a atenção para a determinação do conteúdo do sistema hegeliano - a liberdade. Embora seja um princípio pressuposto na Filosofia do Direito, está demonstrado na Ciência da Lógica. Mas é um princípio que se determina na medida em que se desdobra nas instituições jurídicas. Ora, em Kant, não há a determinação de conteúdo da lei moral. Esta é formal e dada a priori.

\section{Bibliografia}

AVINERI, Shlomo. "Der Staat - das Bewusstsein der Freiheit". In: Materialien zu Hegels Rechtsphilosophie.

V. II, Frankfurt am Main: Suhrkamp, 1974.

BOBBIO, N. Estudos sobre Hegel. Direito, Sociedade Civil, Estado. 2. ed. São Paulo: Brasiliense/UNESP, 1991.

CIRNE LIMA, C. R. "Sobre a contradição pragmática como fundamentação do sistema". In: Sintese Nova

Fase, v. 18, n. 55, 1991.

DOTTI, J. E. Dialéctica y Derecho. El proyecto ético-político hegeliano. Buenos Aires: Hachette S. A. 1983. FLICKINGER, Hans-Georg. Marx e Hegel. São Paulo: LPM/CNPq, 1986.

HEGEL, G. W. F. Grundlinien der Philosophie des Rechts. Frankfurt am Main: Suhrkamp, 1986.

. Enzyklopädie der Philosophischen Wissenschaften, I, II, III. Frankfurt am Main: Suhrkamp, 1986. 
. Wissenschaft der Logik I, II. Frankfurt am Main: Suhrkamp, 1986.

KANT, I. Critica da Razão Prática. Lisboa: Edições 70, 1986.

-__... . Fundamentação da Metafísica dos Costumes. Lisboa: Edições 70, 1986.

. Kritik der praktischen Vernunft/Grundlegung zur Metaphysik der Sitten. Frankfurt am Main: Suhrkamp, v. VII, 1974.

MARX, K. Critica da Filosofia do Direito de Hegel. Lisboa: Presença, 1983.

ROSENFIELD, Denis. Politica e liberdade em Hegel. São Paulo: Brasiliense, 1983.

STEIN, Emildo. Crítica da ideologia e racionalidade. Porto Alegre: Movimento, 1986.

TAYLOR, Charles. Hegel. Frankfurt am Main: Suhrkamp, 1983.

WEBER, Thadeu. Hegel: iberdade, Estado e História. Petrópolis: Vozes, 1993.

WEIL, Eric. Hegel et L'Etat. 6. ed. Paris: VRIN, 1985. 